\title{
A PESSOA COM DEFICIÊNCIA E A SUA INCLUSÃO NO ENSINO SUPERIOR BRASILEIRO
}

Gláucia Cristina Ferreira*

Ivan Dias da Motta**

SUMÁRIO: Introdução; 2 Os direitos da personalidade e a pessoa com deficiência; 30 direito à educação superior da pessoa com deficiência; 4 Avaliação das instituições de ensino superior; 5 Proposta de criação de avaliação propositiva com incentivo; 6 Aluno monitor-auxiliar para a pessoa com deficiência - no ensino superior; 7 Considerações finais; Referência.

RESUMO: A relevância dos direitos da personalidade conforme suas prerrogativas são advindas dos direitos fundamentais do ser humano, porque os direitos da personalidade vêm definidos como direitos essenciais, considerados como o conteúdo mínimo necessário e imprescindível da personalidade humana. Com a atuação do Poder Público busca-se garantir os meios de acesso à educação e comunicativos básicos a todos os cidadãos, incluindo acesso à acessibilidade, somadas às políticas públicas de qualidades e atuação judiciária consciente das obrigações em matéria de direitos humanos. Assegurar o acesso à educação é promover inclusão social, acabando com os grupos fechados, integrando entre si, todos numa mesma comunidade. No trabalho de ajudar as instituições de ensino no país em relação à acessibilidade, com os pressupostos do Sinaes (Sistema Nacional de Avaliação da Educação Superior), pode-se entender o processo da educação inclusiva, que no momento tem se representado um desafio para a educação superior.

PALAVRAS-CHAVE: Direitos da personalidade; Direitos humanos; Pessoa com deficiência; Qualidade no ensino superior; Inclusão e acessibilidade.

\section{DISABLED PEOPLE AND THEIR INCLUSION IN BRAZILIAN HIGHER EDUCATION}

\begin{abstract}
The personality rights, according to their prerogatives, are relevant because they are essential rights to human being, considered as the minimum necessary and essential content of their personality. The performance of the Public Power must guarantee the means of access to education and basic communication

\footnotetext{
Mestre Ciências Jurídicas no Programa de Pós-granduação do Centro Universitário de Maringá - UNICESUMAR, Maringá (PR), Brasil. E-mail: glauciaferreiradv@gmail.com UNICESUMAR. Pesquisador do Instituto Cesumar de Ciência, Tecnologia e Inovação - ICETI, Maringá (PR), Brasil.
}

${ }^{* *}$ Docente Permanente do Programa de Mestrado em Ciência Jurídica do Centro Universitário de Maringá -
\end{abstract}


to all citizens, as well as accessibility, to promote quality public policies and the work of the Judiciary that promotes the guarantee of human rights. Ensuring access to education is to promote social inclusion, which will reduce closed groups and promote the integration of all in the same community. In order to help Brazilian educational institutions to promote accessibility, following the assumptions of Sinaes (National System for the Evaluation of Higher Education), it is possible to understand the challenge of implementing the process of inclusive education in higher education.

KEY WORDS: Personality Rights; Human Rights; Disabled People; Quality in Higher Education; Inclusion and Accessibility.

\section{LA PERSONA CON DEFICIENCIA Y SU INCLUSIÓN EN LA ENSEÑANZA UNIVERSITARIA BRASILEÑA}

RESUMEN: La relevancia de los derechos de la personalidad conforme sus prerrogativas son provenientes de los derechos fundamentales del ser humano, porque los derechos de la personalidad vienen definidos como derechos esenciales, considerados como el contenido mínimo necesario e imprescindible de la personalidad humana. Con la actuación del Poder Público se busca garantizar los medios de acceso a la educación y comunicativos básicos a todos los ciudadanos, incluyéndose acceso a la accesibilidad, sumadas a las políticas públicas de calidades y actuación judiciaria consciente de las obligaciones en materia de derechos humanos. Asegurar el acceso a la educación, es promover inclusión social, acabando con los grupos cerrados, integrando entre sí, todos en una misma comunidad. En el trabajo de ayudar las instituciones de enseñanza en el país en relación a la accesibilidad, con los presupuestos del SINAES (Sistema Nacional de Evaluación de la Educación Superior), puede entenderse el proceso de la educación inclusiva, que en el momento se tiene representado un reto a la educación universitaria.

PALABRAS CLAVE: Derechos de la Personalidad; Derechos Humanos; Persona con Deficiencia; Calidad en la Enseñanza Universitaria; Inclusión y Accesibilidad.

\section{INTRODUÇÃO}

O presente trabalho foi desenvolvido com base na pessoa com deficiência e a sua inclusão no ensino superior brasileiro. A educação superior cumpre atividades que carregam significados importantes, complexos, relacionados com as questões epistêmicas, éticas, políticas, sociais, econômicas, culturais etc. Entretanto, 
essa complexidade não deve ser vista como um empobrecimento que se perde, mas como soluções.

Com o decorrer dos tempos, a pessoa com deficiência que era vista como um "ser castigado" por possuir alguma deficiência e excluído pela sociedade, passou a ganhar olhares de atenção, graças à evolução da raça humana.

Com a chegada dos Direitos da Dignidade Humana, trazendo consigo direitos e obrigações, o artigo $5^{\circ} \mathrm{da}$ Constituição Federal, em seu inciso X, confirma a proteção aos Direitos da Personalidade, assim como no seu artigo $1^{\circ}$ inciso III, fixa a dignidade da pessoa humana entre os fundamentos da República Federativa do Brasil.

Nos objetivos gerais da pesquisa buscou-se demonstrar o respeito à pessoa com deficiência nas tratativas em relação à sua inclusão no ensino superior, conforme o artigo 205 da Constituição Federal, a educação é direito de todos e dever do Estado. Atingindo todos os brasileiros sem distinção, em um mesmo ambiente e o mais diversificado possível, alcançando o pleno desenvolvimento humano e o preparo para a cidadania.

Considerando que a gestão na educaçãoé, por injunção da nossa Constituição do art. 37, que por sua vez, oferece transparência e impessoalidade, autonomia e participação, liderança e trabalho coletivo, representatividade e competência.

Todo esse direito à educação superior, do artigo 205 da CF, se faz necessário ser um dos garantidores para o ensino superior às pessoas com deficiência, e, é chegada a hora de reclamar o que é seu de direito, educação, justa e igualitária.

Buscando o ensino pela inclusão social, encontramos nas instituições de ensino no país (Brasil), em relação à acessibilidade, um documento de metas do PNE 2014-2024 e demais marcos legais e vigentes, que juntamente com os pressupostos do Sinaes $=$ Sistema Nacional de Avaliação da Educação Superior, é possível entender o processo da educação inclusiva.

Ao se aprofundar no estudo, será possível chegar ao ponto da avaliação propositiva com incentivo, que foi criada como uma proposta política, de acompanhamento ao aluno, para saber se o direito do aluno (com deficiência) ao acesso à educação, está sendo garantido, no qual, deve ser seguido conforme prevê a Constituição Federal.

Além deste acompanhamento sobre os seus "direitos", o aluno com deficiência no ensino superior, encontrou apoio no "Aluno Monitor-Auxiliar", que 
atuará como orientador, em diversas tarefas durante o processo de ensino, nas Instituições de Ensino Superior (IES), proporcionando o apoio necessário, até a sua formação.

Todavia, o ingresso desses cidadãos ao ensino superior - com qualidade - tem encontrado obstáculos, por um sistema de atendimento em universidades despreparadas, com barreiras físicas e falta de atendimento especializado, dentre outros problemas.

Tomou-se o cuidado em direcionar esta pesquisa especificamente no ensino superior, na qualidade de ensino e na inclusão da pessoa com deficiência, conforme seus objetivos específicos abordados no desenvolvimento do trabalho, que veremos a seguir.

\section{OS DIREITOS DA PERSONALIDADE E A PESSOA COM DEFICIÊNCIA.}

Desde a época antiga, o termo dos direitos da personalidade já circulava entre os romanos e os gregos. A palavra "persona" - significa: a par de seu equivalente grego prósopon (Prosvpon) - designava a máscara utilizada no teatro. Pela máscara soava, mais alto, a voz do ator. Outra acepção era quando essa máscara (persona) evocava sempre o papel desempenhado pelo ator, a pessoa representava um personagem ou mesmo a figura da personalidade. ${ }^{03}$

Caminham junto com os direitos da personalidade várias ordens como, por exemplo, os direitos pertinentes à proteção da dignidade humana que, para garantir sua real efetividade, preceitua Adriano de Cupis, sobre os direitos da personalidade nada mais é, que um ser titular de direitos e obrigações, constitui a sua pré-condição, ou seja, o seu fundamento e pressuposto. ${ }^{04}$

Olhando este preceito para a pessoa com deficiência, ela é um ser, titular de direitos e obrigações, na qual se constitui o seu fundamento e pressuposto, para que tenha seus direitos garantidos como todos, na busca da inclusão social e no ensino superior, com qualidade.

No artigo $5^{\circ} \mathrm{da} \mathrm{CF}$, inciso $\mathrm{X}$, faz-se a menção aos direitos, à inviolabilidade de determinados direitos da personalidade e no artigo $1^{\circ}$, inciso III, fixa a dignidade

${ }^{03}$ STANCIOLI, Brunello. Sobre os Direitos da Personalidade no Novo Código Civil Brasileiro. Disponível em: http:/hottopos.com/videtur27/brunello.htm\# ftn1 Acesso em: 22 maio 2016.

${ }^{04}$ CUPIS, Adriano de. Os Diretos da Personalidade. 2a Edição: São Paulo. Quorum. 2008. 
da pessoa humana entre os fundamentos da República Federativa do Brasil. ${ }^{05}$

O direito à vida é o mais fundamental de todos os direitos, já que se constitui em pré-requisito à existência e exercício de todos os demais direitos. Os direitos da personalidade são considerados cláusula pétrea constitucional, não morrem pelo seu não uso, e não é possível definir prazos para sua aquisição ou defesa. ${ }^{06}$

Alexandre de Moraes complementa que

Os direitos humanos fundamentais, portanto, colocam-se como uma das previsões absolutamente necessárias a todas as Constituições, no sentido de consagrar o respeito à dignidade humana, garantir a limitação de poder e visar o pleno desenvolvimento da personalidade humana. ${ }^{07}$

Caio Mário da Silva Pereira ressalta que a personalidade do homem é uma faculdade, porém não individualmente, também é reconhecida aos entes morais que constituem um agrupamento de indivíduos ou que se associam para a conquista de um fim econômico ou social..$^{08}$

Quando se busca garantir o pleno desenvolvimento da personalidade humana, estamos tratando de todas as etnias e grupos sociais, assim como as pessoas com deficiências, que buscam seus espaços entre todos, com igualdade e respeito às suas especificidades. $\mathrm{O}$ autor Adriano de Cupis define que

Existem certos direitos sem os quais a personalidade restaria uma susceptibilidade completamente irrealizada privada de todo o valor concreto: direitos sem os quais todos os outros direitos subjetivos perderiam todo o interesse para o indivíduo, o que equivale a dizer que, se eles não existissem, a pessoa não existiria como tal. São esses os chamados "direitos essenciais" com os quais se identificam precisamente os direitos de personalidade..$^{9}$

Os direitos da personalidade com os direitos fundamentais sociais são

\footnotetext{
${ }^{05}$ ANDRADE, Fábio Siebeneichler de. A tutela dos direitos da personalidade no direito brasileiro em perspectiva atual. Revista Derecho del Estado. no.30 Bogotá Jan./June 2013

${ }^{06}$ HEINZMANN, Clara. Fachin, Zulmar. Os Direitos da Personalidade como Direitos Subjetivos Públicos. Revista Jurídica Cesumar - Mestrado, v. 10, n. 1, p. 217-234, jan./jun. 2010.

${ }^{07}$ MORAES, Alexandre de. Direitos humanos fundamentais: teoria geral, comentários aos arts. $1^{\mathrm{o}}$ a $5^{\circ}$ da Constituição da República Federativa do Brasil, doutrina e jurisprudência. 3. ed. São Paulo: Atlas, 2000.p.19.

${ }^{08}$ HEINZMANN, Clara. Fachin, Zulmar. Os Direitos da Personalidade como Direitos Subjetivos Públicos. Revista Jurídica Cesumar - Mestrado, v. 10, n. 1, p. 217-234, jan./jun. 2010.

${ }^{09}$ CUPIS, Adriano de. Op. cit., p. 17.
} 
posições jurídicas do homem que possui pelo simples fato de nascer e viver, são aspectos imediatos da exigência da integração do homem, e ainda são condições essenciais ao seu ser e dever ser. ${ }^{10}$

Consta no artigo $6^{\circ}$ da Constituição Federal que os direitos sociais da educação vem logo após os direitos fundamentais, em que determina que são direitos sociais da educação como a saúde, a alimentação, o trabalho, a moradia, o lazer, a segurança, a previdência social, a proteção à maternidade e à infância, a assistência aos desamparados. ${ }^{11}$

Se tirássemos esses direitos, a personalidade do homem se extinguiria, inexistindo assim, a pessoa, sem direitos e deveres, em que encontraríamos amparo para o ser humano? Onde estaria a proteção para as pessoas com deficiência? Voltaríamos aos tempos das cavernas, quando não havia respeito algum.

De acordo com Paulo Freire, o processo de aprendizagem pode deflagrar no aprendiz uma curiosidade crescente, a qual poderá torná-lo cada vez mais e mais criador, permitindo que o indivíduo aprenda e construa. Neste contexto, o aluno com deficiência encontra poio no monitor de classe e ou um professor especializado, para desenvolver seu aprendizado. ${ }^{12}$

Assim, a educação mostra-se como um componente imprescindível para a formação do homem e da pessoa com deficiência, possibilitando suas reais intenções, junto com os direitos da personalidade, resgatando do homem sua ontologia, para a inclusão social.

\section{O DIREITO À EDUCAÇÃO SUPERIOR DA PESSOA COM DEFICIÊNCIA}

Para a humanidade é consagrado o direito à educação, e esse direito é visto como fundamental, pois a inclusão do direito à educação, conforme o direito fundamental social, está evidenciado no nosso sistema jurídico brasileiro sem distinção ou preconceito.

A Constituição Federal de 1988 incluiu no capítulo II, o denominado "Dos direitos sociais" que, por sua vez, está contido no título II, nomeado de "Dos Direitos

${ }^{10}$ BELTRÃO, Silvio Romero. Direitos da Personalidade - De Acordo com o Novo Código Civil. São Paulo (SP): Atlas, 2005, p. 47-48.

${ }^{11}$ BRASIL. Constituição da República Federativa do Brasil. Brasília: Senado Federal, Centro Gráfico, 1988.

${ }^{12}$ FREITE, Paulo. Pedagogia da autonomia: saberes necessários à prática educativa. $37^{\mathrm{a}}$ Ed. São Paulo: Paz e Terra. 2008. p.24. 
e Garantias Fundamentais", sendo que no artigo 205, está como "direito de todos e dever do Estado". 13

Uma característica da educação como direito fundamental para todos é a sua aplicabilidade imediata (artigo $5^{\circ}, \S 1^{\circ}$ ) e a impossibilidade da sua supressão da ordem constitucional (artigo 60, $\S 4^{\circ}$, inciso IV, todos da CF). O Estado tem a obrigação inescusável de prestar o serviço público essencial da educação a todos os cidadãos, podendo até mesmo ser demandado judicialmente para efetivar seu dever, conforme o artigo $6^{\circ}$ com o 205 da Lei Maior. ${ }^{14}$

A democracia da gestão na educação é, por injunção da nossa Constituição do art. 37, transparência e impessoalidade, autonomia e participação, liderança e trabalho coletivo, representatividade e competência. Com isso, o direito à educação superior, do artigo 205 da CF, se faz necessário ser um dos garantidores para o ensino superior às pessoas com deficiência. ${ }^{15}$

Qualquer cidadão tem o direito à educação e deve exigi-lo do Estado que tem obrigação de fornecer a todos com igualdade.

As pessoas com deficiência precisam, em primeiro lugar, ser ouvidas. Ouvir essas pessoas, sua família e organizações representativas de uma forma menos burocrática, i.e., não só pela tomada de depoimentos e requisições escritas, é algo imperioso para os membros do Ministério Público, em especial para aqueles que detêm algum reconhecimento ou, ao menos, se interessam por estudar o assunto. Somente ouvindo, de forma paciente e comprometida, as problemáticas que afligem as pessoas com deficiência é que se poderão conhecer a fundo os conflitos que cercam esse coletivo. ${ }^{16}$

Para superar os obstáculos do desenvolvimento social, na educação hão de ser incluídos, dentre dos seus componentes, níveis de bem-estar, como procede a atual Constituição, o atendimento às necessidades relativas à sobrevivência e à forma de vida tida como boa, no contexto de uma sociedade. Hoje é alarmante o atraso

\footnotetext{
${ }^{13}$ BRASIL. Constituição da República Federativa do Brasil. Brasília: Senado Federal, Centro Gráfico, 1988.

${ }^{14}$ BRASIL. Constituição da República Federativa do Brasil. Brasília: Senado Federal, Centro Gráfico, 1988.

15 IDEM.

${ }^{16}$ MADRUGA, Sidney. Pessoas com deficiência e direitos humanos: ótica da diferença e ações afirmativas. São Paulo-SP: Saraiva, 2013. p.299.
} 
brasileiro em educação, saúde, habitação, alimentação e saneamento básico. ${ }^{17}$

A pessoa com deficiência tem direito ao ensino superior e com qualidade, já que temos instituições públicas e privadas que a fornecem, então que seja oferecida em igualdade para todos.

O conteúdo mínimo exigível na educação também é versado em diplomas legais, como é o caso da Lei de Diretrizes e Bases da Educação Nacional (lei $\mathrm{n}^{\mathrm{o}}$ 9.394/96) ${ }^{18}$ e do Estatuto da Criança e do Adolescente (lei $\mathrm{n}^{0} 8.069 / 90$, arts. 53 a 59), ${ }^{19}$ bem como das Constituições Estaduais.

Esse direito fundamental à educação possui nota de dupla fundamentalidade, sendo simultaneamente material e formal, pelo seu conteúdo e importância, possui a aplicabilidade imediata a que se refere o art. $5^{\circ}, \S 1^{\circ}$ da CRFB, trazendo consigo a necessidade de busca de uma prestação estatal positiva e imediata visando sua concretização na realidade fática. ${ }^{20}$

A igualdade de condições para o acesso e permanência na escola, o acesso ao ensino obrigatório e gratuito, são direitos públicos subjetivos e a sua negativa de não proporcionar este acesso ao ensino obrigatório pelo Poder Público, ou irregular, importa responsabilidade da autoridade competente conforme trata o art. 208, inciso VII, $\S \S 1^{\circ}$ e $2^{\circ}$ da Carta Magna..$^{21}$

A Declaração Universal dos Direitos do Homem, art. 26 destaca que

Toda a pessoa tem direito à educação. A educação deve ser gratuita, pelo menos a correspondente ao ensino elementar fundamental. O ensino elementar é obrigatório. O ensino técnico e profissional deve ser generalizado; o acesso aos estudos superiores deve estar aberto a todos em plena igualdade, em função do seu mérito. A educação deve visar à plena expansão da personalidade humana e ao reforço dos direitos do homem e das liberdades fundamentais e deve favorecer a compreensão, a tolerância e a amizade entre todas as nações e todos os grupos raciais ou religiosos, bem como

17 BOAVENTURA, Edivaldo M. Direito à Educação. Revista eletrônica Direito UNIFACS - Debate Virtual. Disponível em: www.unifacs.br/revistajuridica/arquivo/edicao_agosto2004/.../doc02.doc Acesso em: 29 maio 2016.

${ }^{18}$ BRASIL. Lei de Diretrizes e Bases da Educação Nacional - LDB (Lei no 9.394/96). Disponível em: http:// www.planalto.gov.br/ccivil_03/leis/L9394.htm Acesso em: 29 maio 2016.

${ }_{19}$ BRASIL. Estatuto da Criança e do Adolescente - ECA (Lei no 8.069/90). Disponível em: http://www.planalto. gov.br/ccivil_03/leis/L8069.htm Acesso em: 29 maio 2016.

${ }^{20}$ ALVAREZ, Monique Modesto Ungar. Ativismo Judicial: o conflito entre a Microjustiça e a Macrojustiça no contexto do Direito Fundamental à Educação. Revista eletrônica Direito UNIFACS - Debate Virtual. Disponível em: http://revistas.unifacs.br/index.php/redu/article/view/3593/2534 Acesso em: 29 maio 16.

${ }^{21}$ BRASIL. Constituição da República Federativa do Brasil. Brasília: Senado Federal, Centro Gráfico, 1988. 
o desenvolvimento das atividades das Nações Unidas para a manutenção da paz.

Os pais têm um direito preferencial para escolher o tipo de educação que será dada aos seus filhos. ${ }^{22}$

Para garantir que seja dada importância na educação superior da pessoa com deficiência é necessário fazer com que todos tenham acesso a ela, a fim de promover a inclusão social, acabar com os grupos fechados e praticar a sociedade com todos, integrando todos entre si, numa mesma comunidade.

Há 45 milhões de pessoas autodeclaradas com deficiência no Brasil, dessas 12 milhões tem ensino médio e 3 milhões ensino superior. Todas as vagas abertas poderiam ser preenchidas por pessoas com nível superior. ${ }^{23}$

Por sua vez, o art. 205 da Constituição da República preceitua que a educação é um direito de todos... Possibilitando o pleno desenvolvimento da personalidade humana, sendo um requisito indispensável à própria cidadania, visando à toda sociedade incluindo a pessoa deficiente, uma educação superior de qualidade. ${ }^{24}$

É evidente todo esse direito e proteção pela Constituição da República, pela Declaração Universal dos Direitos do Homem... O pensamento que fica é: todas as pessoas com deficiência têm esse conhecimento? Se não, a presente pesquisa nasceu para isso, informação.

Tudo isso, vem de frente com a real necessidade que o aluno deficiente encontra nas universidades, que é a necessidade de ter o apoio de um aluno monitor-auxiliar, no intuito de auxiliar o professor a desenvolver o ensino com mais qualidade, conforme determina na Constituição Federal, na qual abordaremos mais à frente.

Diante de todo o exposto, é possível alcançar uma análise sobre os direitos que uma pessoa com deficiência possui, para ser inserido no ensino superior com qualidade, e a sua inclusão num mundo tão moderno e competitivo.

\section{AVALIAÇÃO DAS INSTITUIÇÕES DE ENSINO SUPERIOR.}

\footnotetext{
${ }^{22}$ Declaração Universal dos Direitos do Homem - Lei de 10 de dezembro de 1948. Disponível em: http:// www.humanrights.com/pt/what-are-human-rights/universal-declaration-of-human-rights.html Acesso em: 29 maio 16.

${ }^{23}$ KUZUYABU, Maria. Livre Acesso. Revista Ensino Superior. Ano 18. № 206. Fev.2016. p. 26.

${ }^{24}$ IDEM.
} 
No processo de ensino pela inclusão social, as instituições de ensino no país (Brasil) em relação à acessibilidade, a partir do documento de metas do PNE 2014-2024 e demais marcos legais e vigentes, vêm juntamente com os pressupostos do Sinaes = Sistema Nacional de Avaliação da Educação Superior ${ }^{25}$, entender o processo da educação inclusiva, que no momento tem representado um desafio para a educação superior.

É importante entender as características da acessibilidade e como isso funciona no Instrumento de Avaliaçãa ${ }^{26}$, com orientações necessárias ao processo de avaliação in $l o c 0^{27}$ e a promoção da acessibilidade nas IES, visando à integração entre o órgão avaliador e as IES avaliadas.

O Sinaes foi criado pela lei $\mathrm{n}^{\circ} 10.861$, de 14 de abril de 2004 , ele é formado por três componentes principais sendo: 1 - avaliações nas instituições, 2 - nos cursos e 3 - no desempenho dos estudantes; avalia todos os aspectos que giram em torno desses eixos: o ensino, a pesquisa, a extensão, a responsabilidade social, o desempenho dos alunos, a gestão da instituição, o corpo docente, as instalações e vários outros aspectos.

Com o Sinais surgiu o tripé avaliativo: 1. Avaliação institucional que se opera por meio do credenciamento e recredenciamento de Instituições de Educação Superior; 2. avaliação de cursos, que se divide nas autorizações de cursos, nos seus reconhecimentos e renovações de reconhecimentos; 3. Exame Nacional de Desempenho dos Estudantes - Enade - que avalia cursos de graduação. ${ }^{28}$

Os processos avaliativos são coordenados e supervisionados pela Comissão Nacional de Avaliação da Educação Superior (Conaes), que é órgão colegiado de coordenação e supervisão do Sinaes, sistematizados em Instrumentos de Avaliação elaborados pelo INEP e sua operacionalização é de responsabilidade do Inep. ${ }^{29}$

As informações obtidas com o Sinaes são utilizadas pelas IES, para orientação institucional e efetividade acadêmica e social, pelos órgãos governamentais para orientação das políticas públicas e pelos estudantes, pais de alunos, instituições

\footnotetext{
${ }^{25}$ BRASIL - INEP - Instituto Nacional de Estudos e Pesquisas Educacionais Anísio Teixeira. Disponível em: http://portal.inep.gov.br/superior-sinaes Acesso em: 24 Junho 2016.

${ }_{26}$ BRASIL - INEP - Instituto Nacional de Estudos e Pesquisas Educacionais Anísio Teixeira - Instrumento de Avaliação de Cursos de Graduação presencial e a distância. Brasília, Junho de 2015. Disponível em:

http://download.inep.gov.br/educacao_superior/avaliacao_cursos_graduacao/instrumentos/2016/ instrumento_2016.pdfAcesso em: 03 set. 2016.

27 "In loco" - quando a avaliação é realizada na instituição de ensino, no local.

${ }^{28}$ NUNES, Edson de Oliveira. Educação Superior no Brasil: estudos, debates, controvérsias. Com equipe e colaboradores do Observatório Universitário. Rio de Janeiro: Garamond, 2012. p.396.

${ }^{29}$ NUNES, Edson de Oliveira. Op. Cit., p.396.
} 
acadêmicas e público em geral, para orientar suas decisões quanto à realidade dos cursos e das instituições.

A acessibilidade visa na forma da lei garantir o acesso às IES para todos os acadêmicos com deficiência e os com Necessidades Educacionais Especiais (NEEs) com respeito ao seu direito de matrícula e permanência no ensino superior, respeitando as diferenças e fornecendo condições de igualdade e oportunidade.

$\mathrm{Na}$ avaliação da educação também tem a questão da qualidade.

A qualidade está no centro da agenda atual e dos debates mais agudos da educação superior. Duas concepções distintas disputam a hegemonia de seus significados possíveis: a perspectiva social, daqueles que entendem e procuram realizar a educação como bem público, e o ponto de vista e os interesses defendidos por aqueles que submetem a educação ao mercado. ${ }^{30}$

Buscando ampliar o conhecimento sobre a avaliação institucional, avalia-se bem, como a respeito da possibilidade dos fatores socioculturais, raça e etnia, sexo, formação em escola pública ou particular, culturas estudantis, fatores determinantes para o desempenho acadêmico. ${ }^{31}$

Outra forma de avaliar são os Indicadores de Qualidade, que de acordo com a portaria $\mathrm{n}^{\mathrm{O}}$ 40, de 12 de dezembro de 2007, art. 33-B, são obtidos com base no Enade e em demais insumos constantes das bases de dados do MEC, segundo metodologia própria, aprovada pela Conaes e atendidos os parâmetros da lei $\mathrm{n}^{\mathrm{o}}$ 10.861, de 14 de abril de $2004 .^{32}$

Em 2014 registraram-se 31.866 avaliações de graduação pelo Enade a cada três anos, permitindo que a IES acompanhe e reveja sua melhora de anos anteriores. Desde 2012, com os instrumentos de avaliação, é possível realizar o

\footnotetext{
${ }^{30}$ NUNES, Edson de Oliveira. Op. Cit., p.430.

${ }^{31}$ MORAES, Dislane Zerbinatti. GALLEGO, Rita de Cassia. SILVA, Vivian Batista da. Desafios da Avaliação no Ensino Superior: um exame dos discursos presentes em periódicos educacionais brasileiros (2000-2010). ATAS do VI Encontro do CIED. I Encontro Internacional em Estudos Educacionais. Avaliação: Desafios e Riscos. 2010. p. 292.

${ }^{32}$ BRASIL - Portaria Normativa No 40, de 12 de dezembro de 2007. Institui o e-MEC, sistema eletrônico de fluxo de trabalho e gerenciamento de informações relativas aos processos de regulação, avaliação e supervisão da educação superior no sistema federal de educação, e o Cadastro e-MEC de Instituições e Cursos Superiores e consolida disposições sobre indicadores de qualidade, banco de avaliadores (Basis) e o Exame Nacional de Desempenho de Estudantes (ENADE) e outras disposições. Disponível em: http://abmes.org.br/arquivos/ legislacoes/Portaria_Normativa 40-2007 - republicada.pdf Acesso em: 26 fev. 2017.
} 
acompanhamento por indicadores de qualidade..$^{33}$

Nesses quase 13 anos de implantação do Sinaes $^{34}$ tem se mostrado como é a sua organização, mudanças foram incorporadas, novos indicadores e novas formas de avaliar, assim como as formações de avaliadores com a possibilidade de fazer a avaliação in loco, e também as informações produzidas pelos censos em redes de educação superior, como requisito legal, o Estado brasileiro avançou na proposta de avaliação da educação superior.

No contexto da deficiência,

A igualdade de oportunidades pode ser definida como eliminação de impedimentos físicos, econômicos, sociais ou culturais que de alguma forma restrinjam ou excluam as pessoas com deficiência de sua plena participação e desenvolvimento na sociedade, mediante uma série de medidas inclusivas que englobam a acessibilidade universal; um sistema educacional especializado; condições de trabalho justas, favoráveis e de remuneração digna, programas e serviços de saúde adequados, dentre outras inseridas no processo de luta pela inclusão social desse coletivo. ${ }^{35}$

Edson Nunes defende que a educação superior e a educação em geral têm consequências importantes para a sociedade, como as dimensões sociais, culturais e econômicas. Nada impede que a educação superior seja orientada para contribuir com o aprimoramento socioeconômico de regiões. ${ }^{36}$

Trabalhando na redução da pobreza, a inclusão da pessoa com deficiência e a cultura cívica do país busca formar mais profissionais específicos. Por isso, a importância da política de inclusão na educação superior brasileira, para atendimento às pessoas com deficiência.

\footnotetext{
${ }_{33}$ GRIBOSKY, Claudia Maffini. Competitividade e mudanças no DNA Institucional: construindo a educação superior do futuro. Organização por: REIS, Fabio Garcia. São Paulo: Ed.de Cultura, 2014. p. 126.

${ }^{34}$ BRASIL - Portaria Normativa No 40, de 12 de dezembro de 2007. Institui o e-MEC, sistema eletrônico de fluxo de trabalho e gerenciamento de informações [...] outras disposições. Disponível em: http://abmes.org. br/arquivos/legislacoes/Portaria_Normativa_40-2007_-_republicada.pdf Acesso em: 26 fev. 2017.

${ }^{35}$ MADRUGA, Sidney. Pessoas com deficiência e direitos humanos: ótica da diferença e ações afirmativas. São Paulo-SP: Ed. Saraiva, 2013. p.126.

${ }^{36}$ NUNES, Edson de Oliveira. Educação Superior no Brasil: estudos, debates, controvérsias. Com equipe e colaboradores do Observatório Universitário. Rio de Janeiro: Ed. Garamond, 2012. p.569.
} 


\section{PROPOSTA DE CRIAÇÃO DE AVALIAÇÃO PROPOSITIVA COM INCENTIVO}

A avaliação propositiva com incentivo foi criada como uma proposta política, de acompanhamento ao aluno, para saber se o direito do aluno (com deficiência) ao acesso na educação está sendo garantido, no qual deve ser seguido conforme se prevê na constituição.

O objetivo dessa avaliação é proporcionar acesso ao ensino superior (de qualidade) às pessoas com deficiência, porque isso é garantir o seu direito à educação, sendo também um direito da personalidade humana.

A avaliação da educação superior não pode perder o seu foco principal, para também não perder sua eficácia social e pedagógica. Sua referência central são os papéis essenciais da educação superior. A responsabilidade social de uma instituição educativa diz respeito ao cumprimento, com qualidade, no sentido social e público. ${ }^{37}$

Mas como associar a avaliação com a inclusão da pessoa com deficiência no ensino superior? No campo das avaliações educacionais temos que

Por meio destes instrumentos, o MEC assume a responsabilidade atribuída pela LDB de "assegurar processo nacional de avaliação do rendimento escolar no ensino fundamental, médio e superior, em colaboração com os sistemas de ensino, objetivando a definição de prioridades e a melhoria da qualidade do ensino" e de "assegurar processo nacional de avaliação das instituições de educação superior, com a cooperação dos sistemas que tiverem responsabilidade sobre este nível de ensino". ${ }^{38}$

O processo de avaliação nacional das instituições de educação superior é de responsabilidade do MEC que assume este papel, conforme a LDB atribui. Responsabilidade essa, que também é social, a todos, inclusive às pessoas com deficiência.

Por razões opostas, as reformas educativas sinalizam na mesma direção e elegem a avaliação como sua bandeira em prol da qualidade do ensino.

\footnotetext{
${ }^{37}$ NUNES, Edson de Oliveira. Op. Cit., p. 569.

${ }^{38}$ CASTRO, Maria Helena Guimarães de. Sistemas nacionais de avaliação e de informações educacionais. SÃO Paulo em Perspectiva, 14(1), 2000. p. 124.
} 
As mudanças sustentam-se em visões morais de melhora, ou seja, em valores, formas de convivência e escolhas que realizam as coletividades (e inclusive, nas omissões que realizam ativamente). Contrariar esse substrato é tentar ocultar a própria raiz da ação humana; mas assumi-lo supõe aceitar o debate e a discussão sobre o que significa, ao menos para a coletividade, para a comunidade e para a sociedade onde está situada, uma educação de qualidade. ${ }^{39}$

Valores, formas de convivência e escolhas que realizam as coletividades e mudanças, sustentam-se em visões morais de melhora para a comunidade e para a sociedade onde está situada, alcançando uma educação de qualidade.

Então, oferecendo o ensino, estaria o problema resolvido? Não, não basta apenas inserir o aluno com deficiência no ensino superior, tem que oferecê-lo com qualidade e respeito.

Passamos a ver os tipos de avaliações no ensino, na qual, buscou-se uma classificação segundo sua finalidade, como os modelos educativos, ou formativos.

a) cuja principal finalidade é desenvolver e aprimorar a qualidade do trabalho produzido pela instituição avaliada. Este modelo é caracterizado pela ênfase na análise qualitativa e incentiva o envolvimento de todos os segmentos da instituição na construção e execução do processo, portanto é participativo e mais democrático;

b) os modelos regulatórios, cuja principal finalidade é garantir o cumprimento das regras de funcionamento preestabelecidas para o sistema, garantindo, consequentemente, o nível de qualidade do trabalho das instituições avaliadas. O modelo tem, como principal característica, a ênfase na análise quantitativa, sendo tecnocrático e centralizador. ${ }^{40}$

Ao se fazer a avaliação das instituições de ensino, de exigir que elas atendam aos critérios adotados, consegue-se que elas fiquem mais parecidas umas com as outras. Dessa forma, a avaliação termina padronizando as instituições, independentemente das suas características, e isto não implica necessariamente

\footnotetext{
39 ANGULO, Felix R. O planejamento da qualificação da escola: o leigo graal da mudança educacional In: MURILLO, F.J.; REPISO, M. M et AL. A qualificação da escola. Um novo enfoque. Porto Alegre: Artmed, 2007. p. 128.

${ }^{40}$ LORDÊLO, Jose Albertino Carvalho. DAZZANI, Maria Virgínia. (Organizadores). Avaliação educacional: desatando e reatando nós. - Salvador: EDUFBA, 2009. p.61 e 62.
} 
maior ou menor qualidade. ${ }^{41}$

A política pública é importante no processo de avaliação, permite estudar o Sinaes, levando em consideração as suas características e as estratégias utilizadas para a sua implementação. Acerca da necessidade da criação de uma política de avaliação para a educação superior, temos o seguinte pronunciamento:

Tratava-se, pois, urgente a criação de um Sistema Nacional de Avaliação da Educação Superior (SINAES) a fim de suprir esta lacuna das políticas educacionais - diagnosticada desde o primeiro Programa de Governo do Presidente Luiz Inácio Lula da Silva, cuja orientação era clara: Uma política de ensino superior precisa apoiar-se em pressupostos acadêmicos e políticos que indiquem claramente sua fundamentação doutrinária.

[...] O enfoque adotado conduz à problemática das complexas relações entre saber e poder, propondo uma nova política capaz de refundar a missão pública do sistema universitário brasileiro, respeitando sua diversidade, mas tornando-o compatível com as exigências de qualidade, relevância social e autonomia universitária. ${ }^{42}$

Respeitando as diversidades, mas tornando-as compatíveis com as exigências de qualidade, relevância social e autonomia universitária, foi necessária a criação do Sinais, a fim de suprir esta lacuna nas políticas educacionais, proporcionando uma avaliação propositiva com incentivo, em que o Sinais atua como forma de acompanhamento ao aluno, resguardando seu direito à educação, como deve ser no processo de avaliação junto com o Ministério da Educação - MEC.

O Sistema Nacional da Avaliação da Educação Superior - Sinaes tem por finalidade a melhoria da qualidade da educação superior, orientando a expansão da sua oferta, o aumento permanente da sua eficácia institucional e efetividade acadêmica e social e, especialmente, a promoção do aprofundamento dos compromissos e responsabilidades sociais das instituições de educação superior. ${ }^{43}$

$\mathrm{Na}$ avaliação das instituições, deve-se cuidar para respeitar as diversidades e as especificidades das diferentes organizações acadêmicas, devendo ser contemplada,

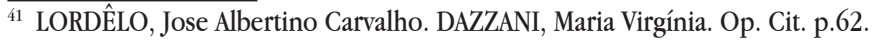

${ }^{42}$ TRINDADE, H. Desafios, institucionalização e imagem pública da CONAES. Brasília, DF: UNESCO/MEC, 2007. p.12.

43 BRASIL. Lei № 10.861 , de 14 de abril de 2004. Institui o Sistema Nacional de Avaliação da Educação Superior - SINAES e dá outras providências. Disponível em: http://www.planalto.gov.br/ccivil 03/ ato2004-2006/2004/lei/110.861.htm Acesso em: 26 março 2017.
} 
no caso das universidades, de acordo com critérios estabelecidos em regulamento, conforme a avaliação mantida pela Fundação Coordenação de Aperfeiçoamento de Pessoal de Nível Superior - Capes. ${ }^{44}$

Sidney Madruga complementa.

Urge revelar que o entendimento pelo Ministério Público Federal é o mesmo adotado pelo Ministério da Educação (MEC) [...]. A isso se acrescenta a Portaria $\mathrm{N}^{0} 3.284 / 2003$, oriunda do MEC, que determina novos critérios para efeito de autorização, reconhecimento credenciamento e renovação de IES, a acessibilidade de pessoas com deficiência ao ensino superior a partir do cumprimento de uma série de requisitos. ${ }^{45}$

Os requisitos legais e normativos exigidos no momento da avaliação são essencialmente regulatórios, não fazem parte do cálculo do conceito da avaliação, do curso (CC), os avaliadores apenas fazem o registro do cumprimento "sim" ou "não" do dispositivo legal e normativo por parte da instituição. ${ }^{46}$

Porém, o seu não atendimento gera uma série de problemas na avaliação, levando até a travar o processo avaliativo e não conseguir tão logo a portaria de autorização de funcionamento do curso ou da instituição (credenciamento).

Dentre vários requisitos legais, no que tange à acessibilidade, podemos destacar:

a) atendimento ou não da Proteção dos Direitos da Pessoa com Transtorno do Espectro Autista, conforme disposto na lei $\mathrm{N}^{\circ} 12.764$, de 27 de dezembro de 2012.

b) Condições de acessibilidade para pessoas com deficiência ou mobilidade reduzida, conforme disposto na $\mathrm{CF} / 88$, art. 205, 206 e 208, na NBR 9050/2004, da ABNT, na lei $\mathrm{N}^{\circ} 10.098 / 2000$, nos decretos $n^{\circ} 5.296 / 2004, n^{\circ} 6.949 / 2009, n^{\circ} 7.611 / 2011$ e na portaria $n^{\circ} 3.284 / 2003$;

c) Disciplina de Libras (Dec. $\left.n^{\circ} 5.626 / 2005\right) ; ;^{47}$

\footnotetext{
${ }_{44}$ IDEM.

${ }^{45}$ MADRUGA, Sidney. Pessoas com deficiência e direitos humanos: ótica da diferença e ações afirmativas. São Paulo-SP: Ed. Saraiva, 2013. p.315.

${ }^{46}$ BRASIL - INEP - Instituto Nacional de Estudos e Pesquisas Educacionais Anísio Teixeira. Diretoria de Avaliação da Educação Superior - Daes. - Instrumento de Avaliação de Cursos de Graduação - presencial e a distância. Brasília, agosto de 2015. p. 54 .

${ }^{47}$ IDEM.
} 
A realização da avaliação das instituições, dos cursos será responsabilidade do Inep. O Ministério da Educação tornará público e disponível o resultado da avaliação das IES e de seus cursos. ${ }^{48}$

Os responsáveis pela prestação de informações falsas ou pelo preenchimento de formulários e relatórios de avaliação que impliquem omissão ou distorção de dados a serem fornecidos ao Sinaes responderão civil, penal e administrativamente por essas condutas. ${ }^{49}$

Urge a obrigação de realizar a avaliação como determina a lei, passando por todos os critérios e normas avaliativas, onde carrega consigo uma série de requisitos legais avaliativos, em prol da qualidade do ensino, especificamente a toda pessoa (igualdade) e às pessoas com deficiências, com apoio na política de inclusão da educação superior brasileira.

Edson Nunes acrescenta que

O credenciamento de instituições, autorizações de cursos superiores e aumento de vagas, também deverão conter proposta específica com análise crítica e propositiva que atenda aos critérios de necessidade e responsabilidade social das instituições de educação superior, redução de desigualdades sociais e regionais, e ações afirmativas na promoção de igualdade de condições com vistas à inclusão social. ${ }^{50}$

Encontra-se na Constituição da República Federativa do Brasil que o acesso efetivo de pessoas com deficiência ao ensino superior de qualidade com enfoque no seu art. 205, aduz ser, que a educação é direito de todos, eliminando-se qualquer obstáculo discriminatório que interfira neste processo. ${ }^{51}$

Segundo a OIT, especificamente o Setor de Coordenação de Igualdade e Direitos Humanos, a quem compete avaliar os programas de ação afirmativa, superar discriminação no emprego, minorias étnicas e pessoas com deficiência etc., especifica as

$\overline{48}$ BRASIL. Lei $N^{0} 10.861$, de 14 de abril de 2004. Institui o Sistema Nacional de Avaliação da Educação Superior - SINAES e dá outras providências. Disponível em: http://www.planalto.gov.br/ccivil_03/_ ato2004-2006/2004/lei/10.861.htm Acesso em: 26 março 2017.

${ }^{49}$ BRASIL. Lei № 10.861, de 14 de abril de 2004. Institui o Sistema Nacional de Avaliação da Educação Superior - SINAES e dá outras providências. Disponível em: http://www.planalto.gov.br/ccivil_03/_ ato2004-2006/2004/lei/110.861.htm Acesso em: 26 março 2017.

${ }^{50}$ NUNES, Edson de Oliveira. Educação Superior no Brasil: estudos, debates, controvérsias. Com equipe e colaboradores do Observatório Universitário. Rio de Janeiro: Garamond. 2012. p.547.

${ }^{51}$ BRASIL. Constituição da República Federativa do Brasil. Brasília: Senado Federal, Centro Gráfico, 1988. loc. cit. 
medidas afirmativas como "providenciais" destinadas a eliminar e compensar quaisquer desigualdades de fato. ${ }^{52}$

No âmbito do Sistema Internacional de Proteção dos Direitos Humanos, as ações afirmativas é tomada como "medidas afirmativas", já no Convênio sobre a Readaptação Profissional e Emprego de Pessoas Inválidas utiliza o termo como "medidas positivas especiais" para lograr igualdade efetiva de oportunidade e de tratamento entre trabalhadores com deficiência. ${ }^{53}$

Por fim, a Convenção sobre os Direitos das Pessoas com Deficiência que trata de temas como educação, saúde, emprego, exploração e violência etc., dispõe no art. $5^{\circ}$ como "medidas apropriadas" para promover a igualdade e eliminar a discriminação e no (art. 5. 3) especifica como "medidas específicas" necessárias para acelerar ou alcançar a efetiva igualdade (art. 5.4), revelando a adição de ações afirmativas num documento internacional dedicado às minorias. ${ }^{54}$

Qual medida será dada ao aluno com deficiência, que pretende ingressar no ensino superior a fim de ajudá-lo? Com base no permissivo constitucional da autonomia universitária e observados os princípios da razoabilidade e proporcionalidade, podem as universidades estabelecer normas de acesso, mediante o implemento de medidas propositivas de ações afirmativas.

A exemplo disso seguem propostas para as IES expandirem seus trabalhos com os alunos deficientes, sendo realizado com o programa de atendimento, conhecido como Núcleo de Atendimento na Instituição (NAI) ou Serviço de Acessibilidade e Apoio Psicopedagógico (SAAP).

OFERECENDO: a) Professores habilitados a prestar atendimento educacional especializado. (Curso profissionalizante) Com programas de formação continuada, $2 \mathrm{x} /$ ano e promovendo oficinas temáticas de inclusão de alunos com deficiência; b) Suporte a educadores e técnicos especializados: docentes novos e sem experiência na IES, no trato com alunos com deficiência são acompanhados de perto pelo programa até se especializarem; c) Traduções de materiais em braile; d) Recursos de tecnologia assistida: Software que converte arquivos de pdf em áudio; e) Materiais didáticos; f)

\footnotetext{
${ }^{52}$ MADRUGA, Sidney. Pessoas com deficiência e direitos humanos: ótica da diferença e ações afirmativas. São Paulo-SP: Ed. Saraiva, 2013. p.181 e 182.

${ }^{53}$ BRASIL - Decreto No 129, de 22 de maio de 1991. Promulga a Convenção nº 159, da Organização Internacional do Trabalho - OIT, sobre Reabilitação Profissional e Emprego de Pessoas Deficientes. Disponível em: http://www.planalto.gov.br/ccivil_03/decreto/1990-1994/D0129.htm Acesso em: 03 março 17.

${ }^{54}$ BRASIL - Decreto $N^{\circ}$ 6.949, de 25 de agosto de 2009. Promulga a Convenção Internacional sobre os Direitos das Pessoas com Deficiência e seu Protocolo Facultativo, assinados em Nova York, em 30 de março de 2007.
} 
Divisão do tempo em sala de aula para as atividades propostas; g) Grupos de estudos e grupo de apoio para as famílias; h) Acompanhar alunos e orientar os docentes; i) Contratação de profissionais de apoio. Profissional ledor, alocado em sala exclusiva para os dois, na realização de provas; j) Contratação de alunos monitores-auxiliares, para acompanhar as atividades em sala de aula e, fora, como em laboratórios; k) Reajuste dos custos nas mensalidades no ano seguinte; 1) Pós-graduação: Gestão estratégica em diversidade e inclusão. ${ }^{55}$

Proporcionar à IES um norte sobre as diretrizes corretas da acessibilidade na educação; é ter a certeza de poder contribuir para a melhoria de uma sociedade, sendo ela "justa e solidária".

Pelo artigo 209 da CF quando especifica que "o ensino é livre à iniciativa privada", desde que obedecidas às normas gerais da educação nacional, juntamente com o 207 define que, as "universidades gozam de autonomia, obedecendo ao princípio da indissociabilidade". ${ }^{56}$

Já no 208, caput; incisos III e V, da mesma lei, traz que o dever do Estado com a educação será garantido com a efetivação do "acesso aos níveis mais elevados do ensino" e "atendimento educacional especializado aos portadores de deficiência"

Garante ainda, (artigo 212 caput e $\S 3^{\circ}$ ) a União, que aplicará uma porcentagem resultante de impostos para a manutenção e desenvolvimento do ensino, assegurando dar prioridade ao ensino e universalização, aplicando padrão de qualidade nos termos do plano nacional da educação. ${ }^{58}$

A avaliação do MEC deve ser vista como algo que se incorpora, em caráter permanente e definitivo, ao patrimônio da instituição autorizada? Não, não deve ser vista assim, trata-se, na verdade, de um direito que integra o patrimônio coletivo e é conferido, sob determinadas condições, em "delegação" pelo seu titular, o Poder Público, a um terceiro, particular ou ente público. ${ }^{59}$

Assim, para o acesso ao ensino superior com qualidade para as pessoas com deficiências, busca-se o direito à educação com igualdade, respeitados os direitos da dignidade e da personalidade humana, a proposta de avaliação veio como uma

55 KUZUYABU, Maria. Livre Acesso. Revista Ensino Superior. Ano 18. № 206. Fev.2016. p. 23.

${ }^{56}$ BRASIL. Constituição da República Federativa do Brasil. Brasília: Senado Federal, Centro Gráfico, 1988.

57 IDEM.

${ }^{58}$ IDEM.

59 BUCCI, Maria Paula Dallari. O art. 209 da Constituição 20 anos depois. Estratégias do Poder Executivo para a efetivação da diretriz da qualidade da educação superior. Belo Horizonte: Fórum Administrativo. DiT.Ptíblico - FA, allo9, n. 105. p. 48.63, novo2009. p. 57. 
forma de incentivo, e se consubstancia na política de acompanhamento ao aluno, em conformidade da Constituição Federal, sendo acompanhado pelo Ministério da Educação, nas Avaliações de Cursos Superiores.

\section{ALUNO MONITOR-AUXILIAR PARA A PESSOA COM DEFICIÊNCIA - NO ENSINO SUPERIOR}

A acessibilidade e a inclusão social são alguns dos temas mais discutidos e requisitados nesse novo século. Buscando a igualdade de oportunidades e o contorno das barreiras físicas, sensoriais, comunicacionais e/ou atitudinais, há cada vez mais demandas de criação de recursos assistivos para a promoção de uma vida plena para a pessoa com deficiência. ${ }^{60}$

No entanto, tais recursos podem não ser apenas materiais, e sim humanos. Nessa categoria há um profissional com a função de "Cuidador do indivíduo com deficiência”, esse tipo de prestação de serviço é fundamental para a autonomia das pessoas com deficiências, de grau moderado a severo.

A deputada federal, Mara Gabrilli, psicóloga, publicitária, de São Paulo é tetraplégica devido a um acidente de carro ocorrido em 1994, explica que, muitas vezes, o cuidador não tem hora nem jornada certa de trabalho, pois as necessidades das pessoas com deficiência são prementes e essenciais, relacionadas diretamente com as próprias funções vitais e fisiológicas. Conta a deputada:

Sou a prova viva de que ninguém faz nada sozinho. Profissionais cuidadores demonstram solidariedade e respeito diante das limitações alheias, representam um verdadeiro compromisso no resgate da dignidade humana e da valorização da pessoa com deficiência. Muitos abdicam de partes importantes de suas próprias vidas, nos campos profissional, afetivo e pessoal, para poder realizar bem essa tarefa. ${ }^{61}$

\footnotetext{
${ }^{60}$ MANGILI, Ana Raquel Périco. Conheça a profissão do cuidador da pessoa com deficiência. Artigos da: Associação de Deficientes Auditivos, Pais, Amigos e Usuários de Implante Coclear. Disponível em: http://www. adap.org.br/site/index.php/artigos/208-conheca-a-funcao-do-monitor-da-pessoa-com-deficiencia Acesso em: 14 maio 2017.

${ }^{61}$ MANGILI, Ana Raquel Périco. Conheça a profissão do cuidador da pessoa com deficiência. Artigos da: Associação de Deficientes Auditivos, Pais, Amigos e Usuários de Implante Coclear. Disponível em: http://www. adap.org.br/site/index.php/artigos/208-conheca-a-funcao-do-monitor-da-pessoa-com-deficiencia Acesso em: 14 maio 2017.
} 
A Lei Brasileira de Inclusão (LBI), sancionada em julho de 2015 e em vigor desde janeiro de 2016, trouxe inúmeros avanços na legislação relativa à pessoa com deficiência, mas o direito de se ter um cuidador custeado pelo Estado ainda é algo a ser conquistado nos próximos anos. ${ }^{62}$

Por isso, enquanto esse direito não está assegurado financeiramente pelo Estado, a atividade de cuidador da pessoa com deficiência muitas vezes é exercida pela própria família do indivíduo e amigos. E nas escolas como fica isso?

No campo do ensino médio (escolas), há a função do "Cuidador de Alunos" com deficiência, com uma rotina de trabalho que inclui o cuidado e o acompanhamento na locomoção pelas dependências da escola, auxiliar no aprendizado ao copiar a matéria ou, caso o aluno não tenha autonomia motora ou intelectual para tanto, ler e escrever por ele. ${ }^{63}$

Ana Mangili explica que, por isso, vem junto com a função diária de cuidador, que também pode ser denominado de atendente pessoal, e mais específico desse serviço, o monitor de apoio à pessoa com deficiência (MAPD), profissional que garante a inclusão do aluno em classes regulares de ensino ou nas universidades. ${ }^{64}$

$\mathrm{Na}$ área do ensino superior, existe? temos a função do "Aluno Monitor", este atua como "professor", auxiliando os alunos no entendimento da matéria ministrada em sala de aula, sanando dúvidas que não foi possível tirar em sala de aula e ajudando na resolução de exercícios. ${ }^{65}$

Para cada monitoramento oferecido, existe um "Professor Orientador" para a seleção dos monitores e para orientação das atividades desenvolvidas. ${ }^{66}$

Mas quando falamos do aluno com deficiência no ensino superior, como fica? Pensando em todo este contexto apresentado, juntando as informações pesquisadas, foi possível chegar a uma proposta para as IES usarem com seus alunos deficientes, sendo

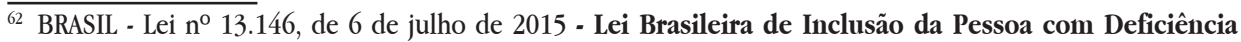
(Estatuto da Pessoa com Deficiência) - NOVO Disponível em: http://www.pessoacomdeficiencia.gov.br/app/ publicacoes/lei-brasileira-de-inclusao-da-pessoa-com-deficiencia-novo Acesso em: 20 fev. 2017.

${ }^{63}$ BRASIL - O que faz: Cuidador de Alunos com Necessidades Especiais. Nova concursos: Cargos Públicos. Disponível em: http://www.novaconcursos.com.br/portal/cargos/cuidador-de-alunos-com-necessidadesespeciais/\#ixzz4h4yS4Stk Acesso em: 14 maio 2017.

${ }^{64}$ MANGILI, Ana Raquel Périco. Conheça a profissão do cuidador da pessoa com deficiência. Artigos da: Associação de Deficientes Auditivos, Pais, Amigos e Usuários de Implante Coclear. Disponível em: http://www. adap.org.br/site/index.php/artigos/208-conheca-a-funcao-do-monitor-da-pessoa-com-deficiencia Acesso em: 14 maio 2017.

${ }^{65}$ PEREIRA. Gabriela Cristina. A Monitoria como auxilio ao processo de ensino-aprendizagem: um estudo de caso no curso de ciências contábeis da Universidade Federal de Santa Catarina. Florianópolis-SC: 2009. p. 37

${ }^{66}$ IDEM. 


\section{o "Aluno Monitor-Auxiliar".}

Cada aluno monitor-auxiliar terá um orientador. Competindo ao aluno monitor, colaborar para com o aluno que irá auxiliar: a) em trabalhos de pesquisa; b) no preparo de material didático; c) na realização de trabalhos didáticos e práticos, em sala de aula ou laboratórios; d) aos monitores de pós-graduação compete também auxiliar nas atividades de graduação; e) na segurança dos dois ao mesmo tempo; f) no acompanhamento em atividades acadêmicas. g) separando a vida pessoal com a acadêmica. ${ }^{67}$

- A função do aluno monitor-auxiliar pode ser oferecida aos alunos matriculados em curso de graduação, que tenham obtido bom rendimento em disciplinas já cursados, bem como por estudantes regularmente matriculados em programa de pós-graduação.

- O aluno monitor-auxiliar pode fazer o acompanhamento para o outro aluno, de grau/curso de ensino igual ou diferente do seu, apenas ajustando seus horários.

- Cada grau de deficiência regerá o tipo de aluno monitor-auxiliar que será designado, pois é necessário verificar o cuidado e o acompanhamento na locomoção pelas dependências da escola, auxiliando no aprendizado ao copiar a matéria ou, caso o aluno não tenha autonomia motora ou intelectual para tanto, ler e escrever por ele.

- Se o aluno deficiente atendido precisa de auxílio com sua higiene, será preciso garantir que ele esteja sempre limpo e asseado. Assim também, como auxiliar o aluno nas idas ao banheiro e, caso o aluno possua autonomia para se limpar sozinho, seu trabalho será de apenas supervisionar as idas ao banheiro.

- Gerando a partir dessas informações o perfil adequado para o aluno deficiente receber o aluno monitor que será mais que isso, irá auxiliá-lo nas demais atividades e necessidades que ele precisar, por isso o nome "aluno monitor-auxiliar", seus cuidados não ficarão apenas na sala de aula e sim nos cuidados pessoais. ${ }^{68}$

${ }^{68}$ PEREIRA. Gabriela Cristina. A Monitoria como auxilio ao processo de ensino-aprendizagem: um estudo de caso no curso de ciências contábeis da Universidade Federal de Santa Catarina. Florianópolis-SC: 2009. p. 
A IES apresentará incentivo aos alunos monitores, por exemplo: I) bolsistas com remuneração; II) sem remuneração, com bolsa e certificado em horas de atividades complementares. $\mathrm{O}$ valor das bolsas dos alunos monitores e o número de vagas pode ser definido anualmente e semestralmente, admitindo-se a recondução. ${ }^{69}$

O recrutamento poderá ser anual e semestral, por meio de processo seletivo podendo conter os seguintes itens: a) exame de ficha da vida escolar do candidato, inclusive do resultado de seus exames de vestibular; b) prova escrita ou prática, relacionada com as atividades que pretende desenvolver; c) entrevista com o docente que será seu orientador; d) exame de ficha da vida pessoal do candidato; e) entrevista com uma psicóloga e pedagogo. ${ }^{70}$

- É permitido incluir no corpo discente, os alunos monitores-auxiliares, as IES poderão constar em seus regimentos as normas que disciplinam o recrutamento e o regime de atividades desses monitores-auxiliares.

- O aluno monitor poderá ser exonerado da função a pedido ou por proposta justificada da coordenação, devendo entregar mensalmente um relatório de atividades de acompanhamento, na coordenação. ${ }^{71}$

Outra proposta que pode ser trabalhada no ensino é a de realizar a contratação de um monitor, "assalariado", como servidor público, quando atua em escolas públicas de ensino fundamental e médio. E, no ensino superior, o contrato de trabalho varia de acordo com cada universidade estadual ou federal, assim como nas escolas e faculdades particulares.

A formação exigida desse profissional é livre (com exceção do intérprete de Libras), podendo a pessoa ter cursado apenas o ensino fundamental, ou ter feito pós-graduação na área educacional, os critérios de escolha, bem como os salários, variam para cada instituição contratante. ${ }^{72}$

A lei $n^{0} 9.394$, de 20 de dezembro de 1996 estabelece as diretrizes e bases

${ }_{69}$ BRASIL - Regulamento de Monitoria. Escola Politécnica de São Paulo - USP. Disponível em: http://www. poli.usp.br/pt/ensino/graduacao/aluno/atendimento-ao-aluno/servico-de-apoio-educacional/ aluno-monitor. html Acesso em: 14 maio 2017.

${ }^{70}$ BRASIL - Regulamento de Monitoria. Escola Politécnica de São Paulo - USP. Disponível em: http://www. poli.usp.br/pt/ensino/graduacao/aluno/atendimento-ao-aluno/servico-de-apoio-educacional/aluno-monitor. html Acesso em: 14 maio 2017.

${ }^{71}$ IDEM.

${ }^{72}$ MANGILI, Ana Raquel Périco. Conheça a profissão do cuidador da pessoa com deficiência. Artigos da: Associação de Deficientes Auditivos, Pais, Amigos e Usuários de Implante Coclear. Disponível em: http://www. adap.org.br/site/index.php/artigos/208-conheca-a-funcao-do-monitor-da- pessoa-com-deficiencia Acesso em: 14 maio 2017. 
da educação nacional, que se inclui do ensino superior, especificando aos discentes da educação superior, poderão ser aproveitados em tarefas de ensino e pesquisa pelas respectivas instituições, exercendo funções de monitoria, de acordo com seu rendimento e seu plano de estudos. ${ }^{73}$

Justifica-se o serviço de monitoria nas escolas e universidades, pois faz parte do Atendimento Educacional Especializado, este garantido por lei, segundo os artigos 227, $\S 1^{\circ}$, inciso II, e 208, inciso III, da Constituição Federal:

O Estado promoverá a criação de programas de prevenção e atendimento especializado para as pessoas portadoras de deficiência física, sensorial ou mental, bem como de integração social do adolescente e do jovem portador de deficiência [...]. ${ }^{74}$

No plano nacional de educação (2011-2020) e a educação especial na perspectiva da educação inclusiva, tem apoio? Sim, vejamos.

Cabe aos sistemas de ensino, ao organizar a educação especial para surdos na perspectiva da educação inclusiva, disponibilizar as funções de instrutor, tradutor/intérprete de Libras e guia intérprete, bem como de monitor ou cuidador aos alunos com necessidade de apoio nas atividades, que exijam auxílio constante no cotidiano escolar, entre outras, de higiene, alimentação, locomoção. ${ }^{75}$

Além das atividades de suporte básico, citadas acima, mais costumeiramente ofertadas aos estudantes com deficiências físicas severas, o serviço de monitoria a pessoas com deficiências sensoriais pode ter funções mais específicas e, às vezes, ser até facultativo ou não recomendado em alguns casos. ${ }^{76}$

O papel do educador vai além de transmitir teorias e de ensinar conteúdos,

73 BRASIL - Lei de Diretrizes e Bases da Educação Nacional - LDB, (Lei no 9.394/96). Disponível em: http:// www.planalto.gov.br/ccivil_03/leis/L9394.htm. Acesso em: 21 maio 2017.

${ }^{74}$ BRASIL. Constituição da República Federativa do Brasil. Brasília: Senado Federal, Centro Gráfico, 1988.

${ }^{75}$ CAMPOS, Arimar Martins. O plano nacional de educação (2011-2020) e a educação especial na perspectiva da educação inclusiva: propostas e desafios. ANPAE - SIMPOSIO. Prefeitura Municipal de Santos - Seduc. 2011. p. 04. Disponível em: http://www.anpae.org.br/simposio2011/cdrom2011/PDFs/ trabalhosCompletos/ comunicacoesRelatos/0074.pdf Acesso em: 14 maio 2017.

${ }^{76}$ MANGILI, Ana Raquel Périco. Conheça a profissão do cuidador da pessoa com deficiência. Artigos da: Associação de Deficientes Auditivos, Pais, Amigos e Usuários de Implante Coclear. Disponível em: http://www. adap.org.br/site/index.php/artigos/208-conheca-a-funcao-do-monitor-da-pessoa-com-deficiencia Acesso em: 14 maio 2017. 
mas também de ensinar a pensar certo, preparando o indivíduo para a vida em sociedade. ${ }^{77}$

A monitoria já existe nos dias de hoje, conforme demonstra a lei, o que se busca é a sua real aplicabilidade, de modo que as instituições de ensino superior passem a aderi-la em prol do aluno deficiente, alcançando assim a satisfação do seu "cliente" e melhorando a qualidade de ensino no país.

\section{CONSIDERAÇÕES FINAIS}

O saber sistemático do direito à educação, parte do reconhecimento do que é mais importante na herança cultural, o cidadão torna-se capaz de se apossar de padrões cognitivos e formativos pelos quais tem maiores possibilidades de participar dos destinos de sua sociedade e colaborar na sua transformação. ${ }^{78}$

$\mathrm{Na}$ avaliação da educação também tem a questão da qualidade. A qualidade geralmente é associada à eficiência nos processos e à eficácia nos resultados, na educação superior procuram realizar a educação como bem público, e o ponto de vista e os interesses defendidos por aqueles que submetem a educação ao mercado.

A política pública é importante no processo de avaliação, permite estudar o Sinaes, levando em consideração as suas características e as estratégias utilizadas para a sua implementação.

A avaliação da educação superior não pode perder o seu foco principal, para também não perder sua eficácia social e pedagógica. Sua referência central são os papéis essenciais da educação superior. A responsabilidade social de uma instituição educativa diz respeito ao cumprimento, com qualidade, no sentido social e público.

O professor e o aluno monitor-auxiliar passam a ser responsáveis por grande parte do conhecimento adquirido pelos alunos, desde o ensino fundamental, até o ensino superior. Com isso, passam a acompanhar os trabalhos do aluno deficiente e o Brasil passa a ampliar o acesso à educação superior, não focando só em números, mas na qualidade do ensino.

Por isso, apresentou-se uma proposta de avaliação como método de

\footnotetext{
77 PEREIRA. Gabriela Cristina. A Monitoria como auxilio ao processo de ensino-aprendizagem: um estudo de caso no curso de ciências contábeis da Universidade Federal de Santa Catarina. Florianópolis-SC: 2009. p. 01 .

${ }^{78}$ CURY, Carlos Roberto Jamil. A gestão democrática na escola e o direito à educação. RBPAE - v.23, n.3, set./dez. 2007. p. 486.
} 
incentivo, para efetivar a inclusão da pessoa com deficiência no ensino superior, conforme a política da educação superior, juntamente com a proposta das IES usarem o "Aluno Monitor-Auxiliar".

Respeitando as diversidades, mas tornando-as compatíveis com as exigências de qualidade, relevância social e autonomia universitária, foi necessária a criação do Sinais, a fim de suprir esta lacuna nas políticas educacionais, proporcionando uma avaliação propositiva com incentivo, realizando o acompanhamento do aluno e com a ajuda do aluno monitor-auxiliar, para a busca do seu direito ao ensino à educação, como deve ser no processo de avaliação junto com o Ministério da Educação - MEC.

\section{REFERÊNCIA}

ALVAREZ, Monique Modesto Ungar. Ativismo Judicial: o conflito entre a Microjustiça e a Macrojustiça no contexto do Direito Fundamental à Educação. Revista eletrônica Direito UNIFACS - Debate Virtual. Disponível em: <http:// revistas.unifacs.br/index.php/redu/article/view/3593/2534>. Acesso em: 29 maio 2016.

ANDRADE, Fábio Siebeneichler de. A tutela dos direitos da personalidade no direito brasileiro em perspectiva atual. Revista Derecho del Estado, Bogotá, no. 30, jan./jun. 2013.

ANGULO, Felix R. O planejamento da qualificação da escola: o leigo graal da mudança educacional. In: MURILLO, F.J.; REPISO, M. M et al. A qualificação da escola: um novo enfoque. Porto Alegre: Artmed, 2007. p. 128.

BELTRÃO, Silvio Romero. Direitos da Personalidade: de Acordo com o Novo Código Civil. São Paulo, SP: Atlas, 2005, p. 47-48.

BOAVENTURA, Edivaldo M. Direito à Educação. Revista eletrônica Direito UNIFACS - Debate Virtual. Disponível em: <www.unifacs.br/revistajuridica/ arquivo/edicao_agosto2004/.../doc02.doc > . Acesso em: 29 maio 2016.

BRASIL - Constituição da República Federativa do Brasil. Brasília: Senado Federal, Centro Gráfico, 1988.

BRASIL. Decreto No 129, de 22 de maio de 1991. Promulga a Convenção no 159 , 
da Organização Internacional do Trabalho - OIT, sobre Reabilitação Profissional e Emprego de Pessoas Deficientes. Disponível em: < http://www.planalto.gov.br/ ccivil_03/decreto/1990-1994/D0129.htm > . Acesso em: 03 março 2017.

BRASIL. Decreto No 6.949, de 25 de agosto de 2009. Promulga a Convenção Internacional sobre os Direitos das Pessoas com Deficiência e seu Protocolo Facultativo, assinados em Nova York, em 30 de março de 2007. Disponível em: $<$ http://www.planalto.gov.br/CCIVIL_03/_Ato2011-2014/2012/Decreto/D7823. htm > . Acesso em: 20 fev. 2017.

BRASIL. Estatuto da Criança e do Adolescente - ECA (Lei no 8.069/90). Disponível em: < http://www.planalto.gov.br/ccivil_03/leis/L8069.htm>. Acesso em: 29 maio 2016.

BRASIL. Instituto Nacional de Estudos e Pesquisas Educacionais Anísio Teixeira. Instrumento de Avaliação de Cursos de Graduação presencial e a distância. Brasília, Junho de 2015. Disponível em: < http://download.inep.gov.br/educacao superior/avaliacao_cursos_graduacao/instrumentos/2016/instrumento_2016.pdf >. Acesso em: 03 set. $201 \overline{6}$.

BRASIL. Lei de Diretrizes e Bases da Educação Nacional - LDB, (Lei ${ }^{\circ}$ 9.394/96). Disponível em: < http://www.planalto.gov.br/ccivil_03/leis/L9394. htm > . Acesso em: 21 maio 2017.

BRASIL. Lei No 10.098, DE 19 de dezembro de 2000. Estabelece normas gerais e critérios básicos para a promoção da acessibilidade das pessoas portadoras de deficiência ou com mobilidade reduzida, e dá outras providências. Disponível em: < http://www.planalto.gov.br/ccivil_03/Leis/L10098.htm>. Acesso em: 19 fev. 2017.

BRASIL. Lei No 10.861, de 14 de abril de 2004. Institui o Sistema Nacional de Avaliação da Educação Superior - SINAES e dá outras providências. Disponível em: < http://www.planalto.gov.br/ccivil_03/_ato2004-2006/2004/lei/110.861.htm>. Acesso em: 26 mar. 2017.

BRASIL. Lei No 12.764, de 27 de dezembro de 2012. Institui a Política Nacional de Proteção dos Direitos da Pessoa com Transtorno do Espectro Autista. Disponível em: < http://www.planalto.gov.br/ccivil_03/_Ato2011-2014/2012/Lei/L12764. htm >. Acesso em: 20 fev. 2017.

BRASIL. Lei no 13.146, de 6 de julho de 2015. Lei Brasileira de Inclusão da 
Pessoa com Deficiência (Estatuto da Pessoa com Deficiência) - NOVO. Disponível em: < http://www.pessoacomdeficiencia.gov.br/app/publicacoes/lei-brasileira-deinclusao-da-pessoa-com-deficiencia-novo > . Acesso em: 20 fev. 2017.

BRASIL. O que faz: Cuidador de Alunos com Necessidades Especiais. Nova concursos: Cargos Públicos. Disponível em: < http://www.novaconcursos.com.br/ portal/cargos/cuidador-de-alunos-com-necessidades-especiais/\#ixzz4h4yS4Stk> . Acesso em: 14 maio 2017.

BRASIL. Portaria Normativa No 40, de 12 de dezembro de 2007. Institui o e-MEC, sistema eletrônico de fluxo de trabalho e gerenciamento de informações relativas aos processos de regulação, avaliação e supervisão da educação superior no sistema federal de educação, e o Cadastro e-MEC de Instituições e Cursos Superiores e consolida disposições sobre indicadores de qualidade, banco de avaliadores (Basis) e o Exame Nacional de Desempenho de Estudantes (ENADE) e outras disposições. Disponível em: < http://abmes.org.br/arquivos/legislacoes/ Portaria_Normativa_40-2007_-_republicada .pdf > . Acesso em: 26 fev. 2017.

BRASIL. Regulamento de Monitoria. Escola Politécnica de São Paulo - USP. Disponível em: < http://www.poli.usp.br/pt/ensino/graduacao/aluno/atendimentoao-aluno/servico-de-apoio-educacional/aluno-monitor.html $>$. Acesso em: 14 maio 2017.

BUCCI, Maria Paula Dallari. O art. 209 da Constituição 20 anos depois: Estratégias do Poder Executivo para a efetivação da diretriz da qualidade da educação superior. Fórum Administrativo. DiT.Ptíblico - FA, Belo Horizonte, allo9, n. 105. p. 48-63, 2009. p. 57.

CAMPOS, Arimar Martins. O plano nacional de educação (2011-2020) e a educação especial na perspectiva da educação inclusiva: propostas e desafios. ANPAE - SIMPOSIO. Prefeitura Municipal de Santos - Seduc. 2011. p. 4. Disponível em: < http://www.anpae.org.br/simposio2011/cdrom2011/PDFs/ trabalhosCompletos/comunicacoesRelatos/0074.pdf> . Acesso em: 14 maio 2017.

CASTRO, Maria Helena Guimarães de. Sistemas nacionais de avaliação e de informações educacionais. São Paulo: Em Perspectiva, v. 14, n. 1, 2000. p. 123-124.

CUPIS, Adriano de. Os Diretos da Personalidade. 2. ed. São Paulo: Quorum. 2008.

CURY, Carlos Roberto Jamil. A gestão democrática na escola e o direito à educação. 
RBPAE, v. 23, n. 3, set./dez. 2007. p. 486-494.

FREITE, Paulo. Pedagogia da autonomia: saberes necessários à prática educativa. 37. ed. São Paulo: Paz e Terra. 2008. p.24.

GRIBOSKY, Claudia Maffini. Competitividade e mudanças no DNA Institucional: construindo a educação superior do futuro. REIS, Fabio Garcia (Org.). São Paulo: Cultura, 2014. p, 123; 125; 126; 130 e 132.

HEINZMANN, Clara. Fachin, Zulmar. Os Direitos da Personalidade como Direitos Subjetivos Públicos. Revista Jurídica Cesumar - Mestrado, v. 10, n. 1, p. 217-234, jan./jun. 2010.

KUZUYABU, Maria. Livre Acesso. Revista: Ensino Superior, ano 18, $\mathrm{n}^{\mathrm{o}} 206$, fev. 2016. p. 23-26.

MADRUGA, Sidney. Pessoas com deficiência e direitos humanos: ótica da diferença e ações afirmativas. São Paulo-SP: Saraiva, 2013. p.126, 181, 182, 221, 247, $248299,315,316,320,322$ e 323.

MANGILI, Ana Raquel Périco. Conheça a profissão do cuidador da pessoa com deficiência. Associação de Deficientes Auditivos, Pais, Amigos e Usuários de Implante Coclear. Disponível em: < http://www.adap.org.br/site/index.php/ artigos/208-conheca-a-funcao-do-monitor-da-pessoa-com-deficiencia $>$. Acesso em: 14 maio 2017.

MORAES, Alexandre de. Direitos humanos fundamentais: teoria geral, comentários aos arts. $1^{\circ}$ a $5^{\circ}$ da Constituição da República Federativa do Brasil, doutrina e jurisprudência. 3. ed. São Paulo: Atlas, 2000.p.19.

MORAES, Dislane Zerbinatti; GALLEGO, Rita de Cassia; SILVA, Vivian Batista da. Desafios da Avaliação no Ensino Superior: um exame dos discursos presentes em periódicos educacionais brasileiros (2000-2010). In: ENCONTRO DO CIED, 7. , ENCONTRO INTERNACIONAL EM ESTUDOS EDUCACIONAIS, 1., 2010. Anais... Avaliação: Desafios e Riscos. 2010. p. 292.

NUNES, Edson de Oliveira. Educação Superior no Brasil: estudos, debates, controvérsias. Rio de Janeiro: Garamond. 2012. p. 33, 40, 396, 405, 406, 407, 421, 430,547 e 569.

PEREIRA, Gabriela Cristina. A Monitoria como auxilio ao processo de ensino- 
aprendizagem: um estudo de caso no curso de ciências contábeis da Universidade Federal de Santa Catarina. Florianópolis, SC: [s.n.], 2009. p. 37

STANCIOLI, Brunello. Sobre os Direitos da Personalidade no Novo Código

Civil Brasileiro. Disponível em: < http:/hottopos.com/videtur27/brunello.htm\# $\mathrm{ftn} 1>$. Acesso em: 22 maio 2016.

TRINDADE, H. Desafios, institucionalização e imagem pública da CONAES. Brasília, DF: UNESCO/MEC, 2007. p.12.

Recebido em: 21 de junbo de 2017 Aceito em: 09 de novembro de 2017 